\title{
Fuzzy control of dual storage system of an electric drive vehicle considering battery degradation
}

\author{
Kemal Keskin ${ }^{*}$ and Burak Urazel \\ Department of Electrical and Electronics Engineering, Eskisehir Osmangazi University, Turkey \\ kkeskin@ogu.edu.tr,burazel@ogu.edu.tr
}

\section{ARTICLE INFO}

\section{Article History:}

Received 02 August 2019

Accepted 02 April 2020

Available 12 December 2020

Keywords:

Fuzzy control

Electric vehicle

Dual storage system

Energy management

AMS Classification 2010:

93C42; 03B52

\begin{abstract}
In this manuscript, fuzzy logic energy management strategy for dual storage system including supercapacitors and battery is proposed in order to prolong battery lifespan and enhance the range of electric drive vehicle (EDV). First an EDV model and three drive cycles (NEDC, UDDS, and NREL) are established in Matlab/Simulink. Then a fuzzy inference system is designed considering three inputs: power demand, state of charge (SOC) of battery and SOC of supercapacitors. An output, which refers to split ratio between supercapacitors and battery power, is determined. Fuzzy rules are constituted in order to decrease not only high level battery current but also number of charge/discharge cycle of battery which are the main factors of battery deterioration. For a performance verification of the proposed method, three drive cycles with different characteristics are considered. Obtained results are compared to two other strategies; one of them is battery only system and the other one is dual storage system managed by logic threshold method. It is shown that the proposed method delivers better and robust performance to prolong battery lifespan.
\end{abstract}

\section{Introduction}

Environmental concerns, which ensued from greenhouse gas emissions and global warming, and energy conservation are two important topics which have attracted increasing attention from researchers over the past few decades. According to Environmental Protection Agency's report, 28.9\% of greenhouse gas emissions were generated only by transportation sector [1]. By means of growing technology, electric drive vehicles come to forefront which have zero-emission engines. Besides that in the sense of energy, EDVs provide exhaustive, and fair energy opportunity that increases efficiency and usage of clean energy sources [2] EDVs are appropriate energy efficient choices for transportation systems, however, as a main energy storage system, battery, has some weaknesses such as: short life cycle, low acceleration performance, and poor power density [3].
There are different aspects of the deterioration of a battery. The charge and discharge cycles of the battery are the main factors of degeneration. If the number of charge/discharge cycles raises, then deterioration accelerates. Another factor is electrical charge/discharge current. Not only high power demands which causes fast discharge but also high charge current affect battery life cycle adversely [4,5]. Supercapacitors do not have much energy capacity as batteries, however, they are capable of delivering and acquiring this energy in very short time due to their high power densities. Therefore supercapacitors are convenient for applications which ensure high-power in order to expedite the vehicle or recover possible energy along braking mode 3,6 . Considering an electric vehicle energy demand, it is more convenient to constitute a dual storage system which consists of both battery and a supercapacitor $[7,8]$. This

*Corresponding author 
storage system conducts battery and supercapacitor in a parallel manner. Thus it has advantage of combining functionality of both energy sources at the same time. Furthermore, performance of electric drive vehicle is improved and the lifespan of battery is extended.

It is required to arrange power management of dual storage system in order to satisfy driving performance and energy efficiency of storage system. In recent years, a variety of power management control strategies have been proposed. These strategies are classified into two main parts: online (real-time) strategies and offline optimization strategies. As an offline optimization method dynamic programming was utilized to control actions and provide power distribution between two energy sources. During the simulations, three different drive cycle were taken into account. With the help of rule based power management, authors indicated that proposed control strategy could improve the performance of system for several state of health $(\mathrm{SOH})$ and state of charge conditions. 9. In another study, a nonlinear controller model developed and this model was evaluated using Lyapunov stability design techniques [10]. The DC bus voltage is also regulated using two DC/DC converters besides battery and supercapacitor currents. A Lyapunov function based controller and a sliding mode controller were proposed to regulate DC bus voltage and currents of battery and supercapacitor respectively [11. Nonlinear control techniques provides reasonable solutions, however, computational complexity is still a drawback.

In recent years, many real-time energy management strategies have been recommended. A twolevel model predictive control algorithm was proposed to control energy management system of a race car under lap time and energy consumption constraints 12. An integrated optimization method was utilized to optimize hybrid energy storage system considering battery degradation and electricity cost. Authors realized the optimization process in terms of battery prices. Finally it is declared that the total cost of hybrid energy system is depicted to be $12 \%$ less than a solo energy storage system [13. In another study authors proposed a Haar wavelet transform in order to manage energy storage system of a tram [14]. A reinforcement learning based approach was applied to hybrid energy storage system. First, power transition matrices based on Markov chain were calculated. Then, reinforcement algorithm was utilized to optimize energy loss of system. The rule based power management and proposed method were compared 15]. Furthermore, Choi et al. proposed a model which consist of two parts: first, supercapacitor's reference voltage was calculated and then power management was optimized. They formulated a convex optimization problem model, subsequently solved this problem using general solvers [5]. Moreno et al. proposed an optimal control strategy based on neural networks which was appropriate for different power sources. They made several experimental tests in several conditions [16]. In order to optimize SOC values and battery life of hybrid energy storage system, Shen and Khaligh formulated a multiobjective optimization problem. They used not only dynamic programming method to solve optimization problem but also fuzzy logic approach for comparison of test results [17]. Stability and quality of distribution network are critical for power grids. In this sense, fuzzy logic controller was applied to energy management system in order to keep battery SOC values in secure limits [18 and to minimize grid power variation [19,20]. Besides these control strategies also heuristic 21] and decentralized [22] controllers were used for energy management of storage systems.

Electric vehicle's performance and energy efficiency of storage system were the focus of algorithms mentioned above. However, complexity of driving cycle changes power demand for various conditions. This situation affects battery's $\mathrm{SOH}$ and SOC substantially. In this manuscript, the main concentration is the energy management of an electric drive vehicle with a dual storage system prioritizing battery's $\mathrm{SOH}$ and SOC states. First, a dual storage system is modeled including battery and supercapacitor. Then, a fuzzy inference system is proposed according to battery and supercapacitor characteristics. Afterward, a fuzzy controller is designed which is appropriate to assemble with electric drive vehicle model in Matlab.

\section{System Description and Modeling}

A simplified longitudinal vehicle model is used in this study in order to estimate the dynamic tractive requirements of the EDV powertrain.

\subsection{Modeling of Electric Drive Vehicle}

Four resistive forces affect the EDV along its motion; aerodynamic drag resistance force $F_{\text {aero }}$, rolling resistance force $F_{\text {roll }}$, road gradient force $F_{\text {grad }}$ and bearing and mechanical friction force $F_{\text {frict }}$. Aerodynamic drag resistance is the drag force created by the friction between vehicle body 
and air flow around the vehicle. It can be expressed as follows:

$$
F_{\text {aero }}=\frac{1}{2} \rho A v^{2} c
$$

where $\rho$ is air density $\left(\mathrm{kg} / \mathrm{m}^{3}\right), A$ is frontal area of the vehicle $\left(\mathrm{m}^{2}\right), c$ is drag coefficient of the vehicle and $v$ is the velocity of the vehicle $(\mathrm{m} / \mathrm{s})$.

Rolling resistance is the required force to overcome the friction between the tires and the road surface and can be represented by

$$
F_{\text {roll }}=m g f_{r} \cos \theta
$$

where $f_{r}$ is rolling friction coefficient, $m$ is mass of the vehicle $(\mathrm{kg}), g$ is gravitational acceleration $\left(\mathrm{m} / \mathrm{s}^{2}\right)$ and $\theta$ is the slope angle of the road (degree). Rolling friction coefficient can be also given as a function of vehicle speed, tire type and tire pressure, hence it can be formulated as follows 23]:

$$
f_{r}=f_{R 0}+f_{R 1}\left(\frac{v}{27.78}\right)+f_{R 4}\left(\frac{v}{27.78}\right)^{4}
$$

In equation (3), values of $f_{R 0}, f_{R 1}$ and $f_{R 4}$ are obtained from three standard graphs for different tire thread patterns and various vehicle speeds 23].

When EDV is moving on a inclined road, a road gradient force considerably affects the vehicle. This gradient force is originated from gravity and can be formulated as:

$$
F_{\text {grad }}=m g \sin \theta
$$

Additionally, rotating mechanical parts of the vehicle such as bearing, shaft, etc. cause some extra friction. This bearing and mechanical resistance can be modeled as [24]:

$$
F_{\text {frict }}=m g k_{\text {frict }}
$$

where $k_{\text {frict }}$ is constant related to bearing and mechanical friction of the vehicle.

Throughout the motion of EDV, the electric motor should overcome all above resistive forces. The required motor power is transmitted to tires through the drive train which consists of gearbox and drive shaft. So, input-output relation of the drive train must be determined implicitly. Shaft parameters such as shaft force, $F_{\text {shaft }}(N)$, shaft power, $P_{\text {shaft }}(W)$, shaft speed, $n_{\text {shaft }}($ rpm $)$ and shaft torque $T_{\text {shaft }}(\mathrm{Nm})$ can be obtained as follows:

$$
\begin{aligned}
F_{\text {shaft }} & =F_{\text {aero }}+F_{\text {roll }}+F_{\text {grad }}+F_{\text {frict }} \\
P_{\text {shaft }} & =F_{\text {shaft }} v \\
n_{\text {shaft }} & =60 \frac{v}{\pi d_{\text {wheel }}} \\
T_{\text {shaft }} & =F_{\text {shaft }} r_{\text {wheel }}
\end{aligned}
$$

where $d_{\text {wheel }}$ is diameter of the wheel $(m)$ and $r_{w h e e l}$ is radius of the wheel $(m)$.

Similarly, motor parameters such as motor torque, $T_{\text {motor }}$, motor speed, $n_{\text {motor }}$ and motor power, $P_{\text {motor }}$ can be calculated by using following equations:

$$
\begin{aligned}
& T_{\text {motor }}=\frac{T_{\text {shaft }}}{\eta_{g} i} \\
& n_{\text {motor }}=n_{\text {shaft }} i \\
& P_{\text {motor }}=\pi n_{\text {motor }} \frac{T_{\text {motor }}}{30}
\end{aligned}
$$

where $\eta_{g}$ is gearbox efficiency and and $i$ is gear ratio. Note that positive $P_{\text {motor }}$ values refer to the motor mode where the vehicle is propelled by electric motor while negative $P_{\text {motor }}$ values refer to the regenerative mode where electric motor acts as a generator and charges the energy storage system that consists of supercapacitor and battery. Since proposed controller takes into account not only the required power but also state of charge values of battery and supercapacitor. In the next subsection, calculation of SOC values of battery and supercapacitor will be explained in detail.

\subsection{Dual Storage System}

By considering the constant auxiliary consumption $P_{a u x}$, battery power $P_{b a t}$ and battery current $I_{\text {bat }}$ are calculated as;

$$
\begin{aligned}
P_{b a t} & =P_{a u x}+\frac{P_{\text {motor }}}{\eta_{m}} \\
I_{b a t} & =\frac{U_{b a t}}{2 R_{b a t}}-\sqrt{\left(\frac{U_{b a t}}{2 R_{b a t}}\right)^{2}-\frac{P_{b a t}}{R_{b a t}}}
\end{aligned}
$$

For any required speed and torque values, motor efficiency $\eta_{m}$ can be obtained from the motor efficiency maps provided by the manufacturer or can be derived experimentally. Likewise battery no-load voltage $U_{b a t}$ and internal resistance $R_{b a t}$ can also be calculated from the battery charge/discharge curves. Assuming 1 hour of run time, total charge of battery $Q_{b a t}$ and battery $S O C\left(S O C_{b a t}\right)$ can be calculated as:

$$
\begin{aligned}
Q_{b a t} & =\int_{0}^{3600} I_{b a t} d t \\
S O C_{b a t} & =\frac{Q_{N}-Q_{b a t}}{Q_{N}}
\end{aligned}
$$

where $Q_{N}$ is the nominal charge of battery.

State of charge value of supercapacitor $S O C_{s c}$ can be calculated in a similar manner by using simplified $\mathrm{RC}$ equivalent model including the ideal capacitor $C$ and the series internal resistance of the supercapacitor $R_{s c}$. Here $R_{s c}$ represents the 
energy loss converted to heat during charge and discharge process of the supercapacitor [25]. The block diagram of the dual storage system is given in Figure 1 .

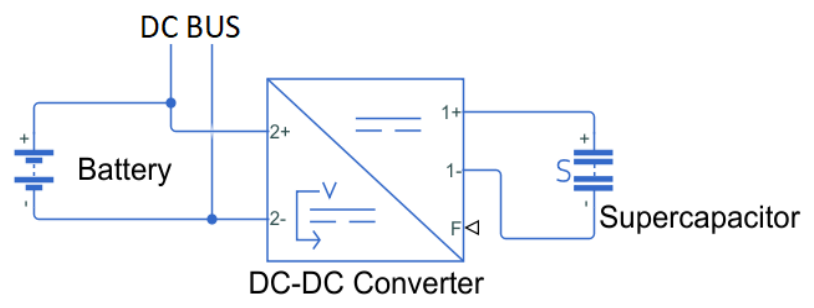

Figure 1. Block diagram of dual storage system

\section{Energy Management Control}

The purpose of energy management controller in the EDV is to allocate the instantaneous power between the battery and supercapacitor considering to prolong battery lifespan and the range of EDV. Controller should respond to the power request on time, however, real-time drive cycles are complex and differ from each other with respect to power demands. Fuzzy control system, which has the advantages of easy construct, robustness and no need to mathematical model in comparison to analytical model-based strategies, can be a good choice for controlling of an energy management system [26].

\subsection{Structure of Fuzzy Controller}

The fuzzy energy management system should specify the allocation between the battery and supercapacitor in order to meet power requirements. Fuzzy inference system generates an output to control power split using three inputs such as: power demand, SOC of battery and SOC of supercapacitor. Both SOC's are defined in the interval of $[0,1]$. So their form is convenient to use with fuzzy inference system. But power demand should be fuzzified before it enters fuzzy inference system. Following equation can be used to fuzzify power demand:

$$
F_{\text {Pdemand }}=\frac{P_{\text {demand }}}{P_{\max }}
$$

where $P_{\text {demand }}$ is the required power, $F_{\text {Pdemand }}$ is fuzzified value of power demand and $P_{\max }$ is the maximum power demand. The fuzzy controller provides power distribution for battery and supercapacitor using output of fuzzy inference system, $m_{\text {bat }}$. Battery power is calculated by following formula:

$$
P_{\text {bat }}=P_{\text {demand }} m_{\text {bat }}
$$

where $P_{b a t}$ is power provided by battery. It is assumed that there is no power loss caused by
DC/DC converter. So, power allocated to supercapacitor, $P_{s c}$, can be calculated by using following formula:

$$
\begin{aligned}
P_{\text {demand }} & =P_{b a t}+P_{s c} \\
P_{s c} & =P_{\text {demand }}-P_{b a t} \quad \text { or } \\
P_{s c} & =P_{\text {demand }}\left(1-m_{\text {bat }}\right)
\end{aligned}
$$

The structure of fuzzy controller is shown in Figure 2

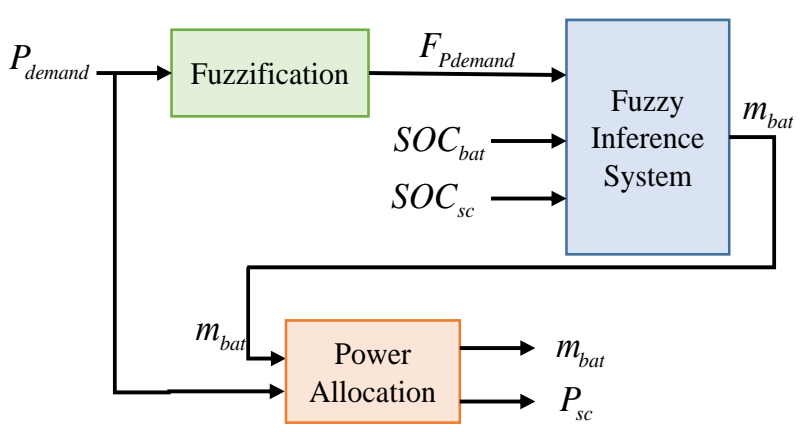

Figure 2. The structure of Fuzzy Controller

\subsection{Modeling Membership Functions of Fuzzy Control}

In order to prolong battery lifespan, it is required to avoid not only frequent charge and discharge of battery but also high battery current. Thus in terms of fuzzy energy management control, supercapacitor should deliver power as much as possible when the power demand is positive, high and the SOC of battery is low. On the contrary, when the power demand is negative and high - regenerative mode -, supercapacitor should be charged as much as possible.

Supercapacitors charge and discharge efficiency is sufficient, however, a SOC level of supercapacitors under $\% 5$ is not desired. Fuzzy rules are constituted considering SOC level of supercapacitors. We can summarize the main idea behind the rules as following: If power demand is high (maximum acceleration mode), then battery and supercapacitor deliver power for the EDV together. If power demand is low (cruising mode), supercapacitor provides the entire power alone. If power demand is negative (braking or regenerative mode), then supercapacitor is charged first, remaining energy charges the battery if there is. The whole rules can be obtained by means of Table1, Table 2, and Table 3 . 
Table 1. Fuzzy rule table for $S O C_{b a t}$ is BL.

\begin{tabular}{|c|c|c|c|c|c|c|}
\hline \multirow{2}{*}{\multicolumn{2}{|c|}{$\begin{array}{c}S O C_{b a t} \\
\mathrm{BL}\end{array}$}} & \multicolumn{5}{|c|}{$S O C_{c a p}$} \\
\hline & & CL & CLM & $\mathrm{CM}$ & CHM & $\mathrm{CH}$ \\
\hline \multirow{7}{*}{ 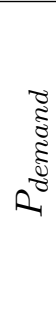 } & $\mathrm{RH}$ & $\mathrm{OM}$ & $\mathrm{OM}$ & $\mathrm{OHM}$ & $\mathrm{OHM}$ & $\mathrm{OH}$ \\
\hline & $\mathrm{RM}$ & OM & $\mathrm{OM}$ & OHM & OHM & $\mathrm{OH}$ \\
\hline & RL & OLM & OLM & OLM & OLM & OHM \\
\hline & $\mathrm{Z}$ & $\mathrm{OM}$ & $\mathrm{OM}$ & $\mathrm{OM}$ & $\mathrm{OM}$ & $\mathrm{OM}$ \\
\hline & $\mathrm{L}$ & OHM & OHM & OLM & OLM & $\mathrm{OL}$ \\
\hline & $\mathrm{M}$ & $\mathrm{OH}$ & OHM & $\mathrm{OM}$ & OM & OLM \\
\hline & $\mathrm{H}$ & $\mathrm{OH}$ & $\mathrm{OH}$ & OHM & OHM & $\mathrm{OM}$ \\
\hline
\end{tabular}

Table 2. Fuzzy rule table for $S O C_{b a t}$ is BM.

\begin{tabular}{|c|c|c|c|c|c|c|}
\hline \multirow{2}{*}{\multicolumn{2}{|c|}{$\begin{array}{c}S O C_{b a t} \\
\mathrm{BM}\end{array}$}} & \multicolumn{5}{|c|}{$S O C_{c a p}$} \\
\hline & & CL & CLM & $\mathrm{CM}$ & CHM & $\mathrm{CH}$ \\
\hline \multirow{7}{*}{ 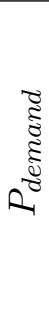 } & $\mathrm{RH}$ & $\mathrm{OL}$ & OLM & OLM & $\mathrm{OM}$ & $\mathrm{OH}$ \\
\hline & $\mathrm{RM}$ & OLM & $\mathrm{OL}$ & OLM & OLM & OHM \\
\hline & RL & OLM & OL & $\mathrm{OL}$ & $\mathrm{OL}$ & OHM \\
\hline & $\mathrm{Z}$ & $\mathrm{OM}$ & $\mathrm{OM}$ & $\mathrm{OM}$ & $\mathrm{OM}$ & $\mathrm{OM}$ \\
\hline & $\mathrm{L}$ & OHM & $\mathrm{OM}$ & OLM & OLM & OLM \\
\hline & $\mathrm{M}$ & OHM & $\mathrm{OHM}$ & $\mathrm{OM}$ & OLM & OLM \\
\hline & $\mathrm{H}$ & OHM & $\mathrm{OHM}$ & OHM & $\mathrm{OM}$ & $\mathrm{OM}$ \\
\hline
\end{tabular}

The domain of fuzzy inference system variable power demand is defined as $[-0.5,1]$ since there is negative power demand for regenerative mode. Furthermore, the domain for the battery SOC and supercapacitor SOC is defined as $[0,1]$ and also the domain for output is defined as $[0,1]$.

Table 3. Fuzzy rule table for $S O C_{b a t}$ is $\mathrm{BH}$.

\begin{tabular}{|c|c|c|c|c|c|c|}
\hline \multirow{2}{*}{\multicolumn{2}{|c|}{$\begin{array}{c}S O C_{b a t} \\
\mathrm{BH}\end{array}$}} & \multicolumn{5}{|c|}{$S O C_{c a p}$} \\
\hline & & CL & CLM & $\mathrm{CM}$ & CHM & $\mathrm{CH}$ \\
\hline \multirow{7}{*}{ 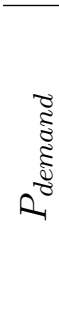 } & $\overline{\mathrm{RH}}$ & 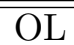 & $\overline{\overline{\mathrm{OL}}}$ & OL & "OLM & "OLM \\
\hline & $\mathrm{RM}$ & OL & $\mathrm{OL}$ & OL & $\mathrm{OL}$ & $\mathrm{OL}$ \\
\hline & RL & OL & $\mathrm{OL}$ & OL & OL & OL \\
\hline & Z & $\mathrm{OM}$ & $\mathrm{OM}$ & $\mathrm{OM}$ & $\mathrm{OM}$ & $\mathrm{OM}$ \\
\hline & $\mathrm{L}$ & $\mathrm{OH}$ & $\mathrm{OHM}$ & OHM & OLM & OL \\
\hline & M & $\mathrm{OH}$ & $\mathrm{OHM}$ & OHM & $\mathrm{OM}$ & OLM \\
\hline & $\mathrm{H}$ & $\mathrm{OH}$ & $\mathrm{OH}$ & $\mathrm{OH}$ & OHM & OLM \\
\hline
\end{tabular}

Fuzzy set for the first input variable is $P_{\text {demand }}=$ $\{R H, R M, R L, Z, L, M, H\}$, where the power demand is split to seven fuzzy linguistics: "Regenerative High" (RH), "Regenerative Medium" (RM), "Regenerative Low" (RL), "Zero" (Z), "Low" (L), "Medium" (M), "High" (H). The second variable's fuzzy set consists of three membership functions: $S O C_{b a t}=\{B L, B M, B H\}$, where "Battery Low" (BL), "Battery Medium" (BM), "Battery High" (BH). The last input variable's fuzzy set is $S O C_{c a p}=\{C L, C L M, C M, C H M, C H\}$ where the linguistics are: "Capacitor Low" (CL), "Capacitor Low Mid" (CLM), "Capacitor Medium" (CLM), "Capacitor High Mid" (CHM), "Capacitor High" (CH). Each linguistic defined above is assigned by a triangular or trapezoidal membership function which is shown in Figure 3
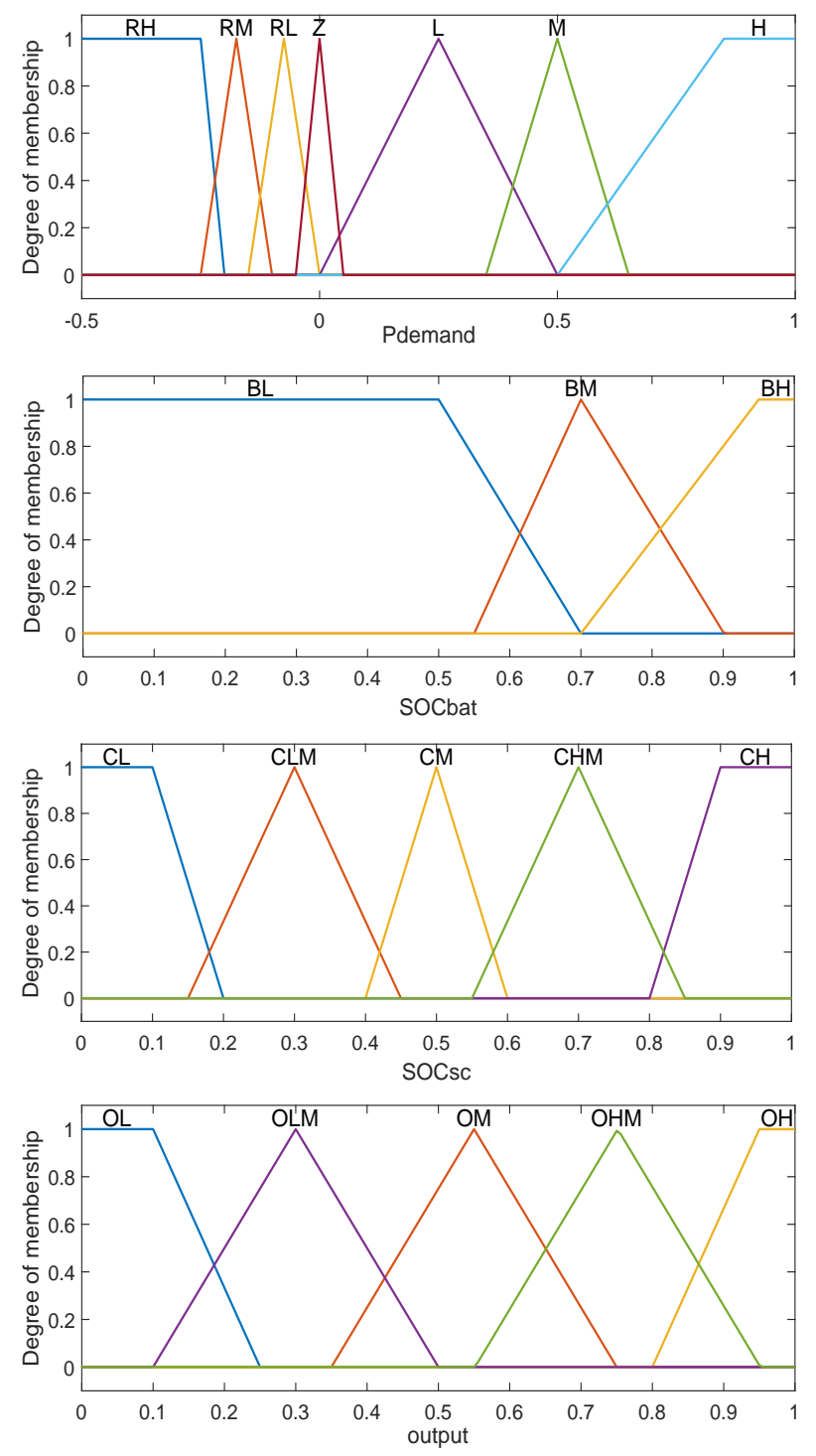

Figure 3. Fuzzy membership functions

A block diagram constituted in Simulink including proposed fuzzy controller, electric drive vehicle model, three different drive cycles and dual storage system which is shown in Figure 4. The fuzzy controller determines the $m_{\text {bat }}$ parameter. Then it specifies the desired power from battery and supercapacitor by using (18)-20.

\section{Simulation Results}

In order to validate the effectiveness of the proposed algorithm, an electrical drive vehicle is modeled as seen Figure 4. The vehicle parameters and the specifications of the dual storage 
system are given in Table 4, Table 5, and Table 6 respectively. The capacities of battery and supercapacitors are determined based on the power requirements obtained from drive cycle simulations.

Table 4. Vehicle Parameters.

\begin{tabular}{lc} 
Parameter & Value \\
\hline \hline$\rho$ & $1.2 \mathrm{~kg} / \mathrm{m}^{3}$ \\
$A$ & $2.36 \mathrm{~m}^{2}$ \\
$C$ & 0.3 \\
$m$ & $1000 \mathrm{~kg}$ \\
$f_{R 0}$ & 0.009 \\
$f_{R 1}$ & 0.0015 \\
$f_{R 4}$ & 0.0012 \\
$k_{\text {frict }}$ & 0.005 \\
$r_{\text {wheel }}$ & $263.5 \mathrm{~mm}$ \\
$\eta_{g}$ & 0.98 \\
$i$ & 8.59 \\
$P_{\text {aux }}$ & $250 \mathrm{~W}$ \\
\hline \hline
\end{tabular}

Three different strategies are applied during simulations. In the first strategy, supercapacitors are ignored and battery is assumed to be the only energy storage system for EDV. In the second strategy, dual storage system with battery and supercapacitor is considered and controlled with traditional logic threshold control method [27,28]. In the third strategy, again, dual storage system is considered and fuzzy control method is applied to manage the storage system.
Table 5. Battery Parameters

\begin{tabular}{llc}
\hline \hline Valence & Number of Modules & $15(15 \mathrm{~s} 1 \mathrm{p})$ \\
UEV-18XP & Peak Load Current & $200 \mathrm{~A}$ \\
Battery & Max. Cont. Current & $120 \mathrm{~A}$ \\
Module & Rated Capacity & $69 \mathrm{Ah}$ \\
& Nominal Voltage & $288 \mathrm{~V}$ \\
\hline \hline
\end{tabular}

Table 6. Supercapacitor Parameters

\begin{tabular}{llc}
\hline \hline Maxwell & Number of Modules & $54(18 \mathrm{~s} 3 \mathrm{p})$ \\
BCAP 3400 & Nominal Voltage & $48.6 \mathrm{~V}$ \\
P270 & Peak Load Current & $2600 \mathrm{~A}$ \\
K04/K05 & Max. Cont. Current & $210 \mathrm{~A}$ \\
\hline \hline
\end{tabular}

Table 7. Characteristics of drive cycles

\begin{tabular}{lccc}
\hline \hline & NEDC & UDDS & NREL \\
\cline { 2 - 4 } Distance $(\mathrm{m})$ & 10932 & 11989 & 10509 \\
Duration $(\mathrm{sec})$ & 1180 & 1372 & 3697 \\
Max. Speed $(\mathrm{km} / \mathrm{h})$ & 120 & 91.25 & 78.42 \\
Average Speed $(\mathrm{km} / \mathrm{h})$ & 33.35 & 31.38 & 10.23 \\
Number of Stops & 13 & 17 & 32 \\
\hline \hline
\end{tabular}

Each strategies are applied for three different drive cycles; New European Drive Cycle (NEDC), Urban Dynamometer Driving Schedule (UDDS) and National Renewable Energy Laboratory Class-3 (NREL Class-3). Characteristics of these drive cycles are given in Figure 5 and Table 7.
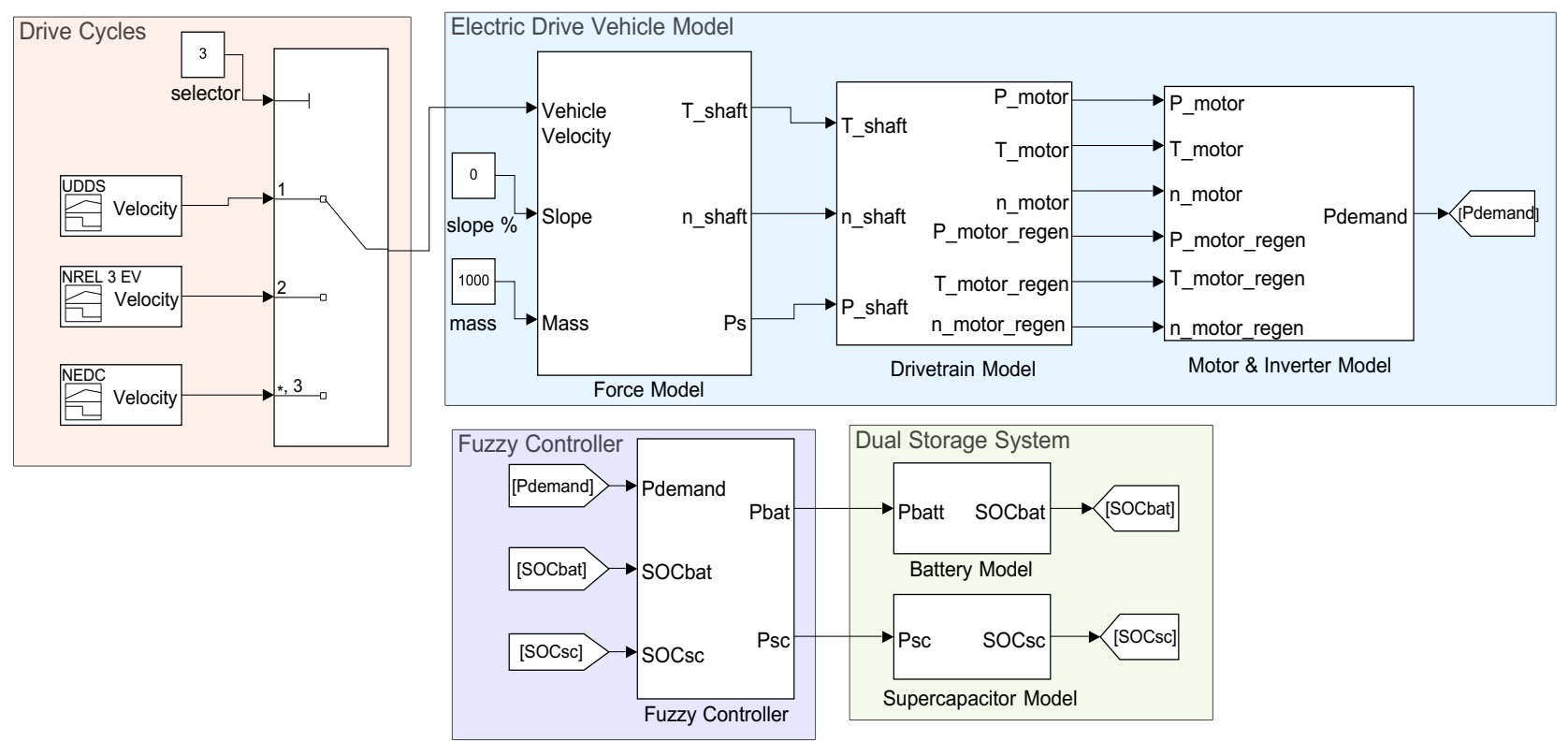

Figure 4. Block diagram of proposed control strategy for EDV with dual storage system 


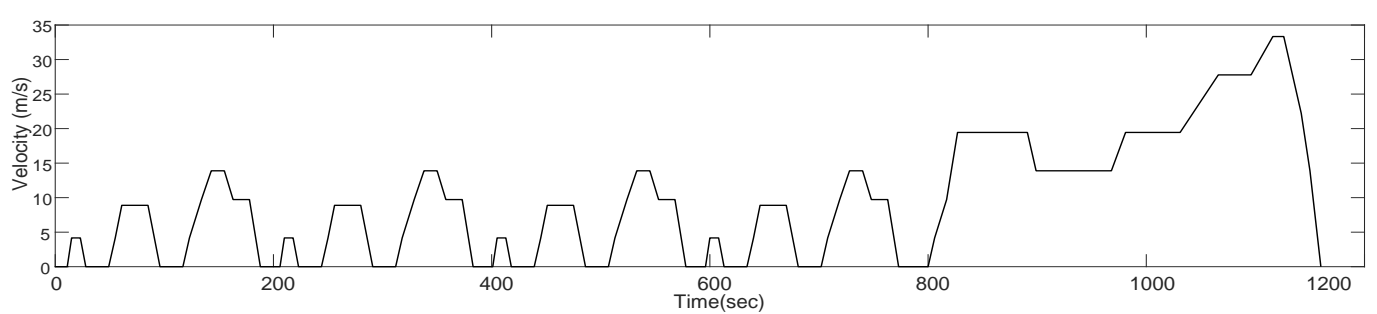

(a)

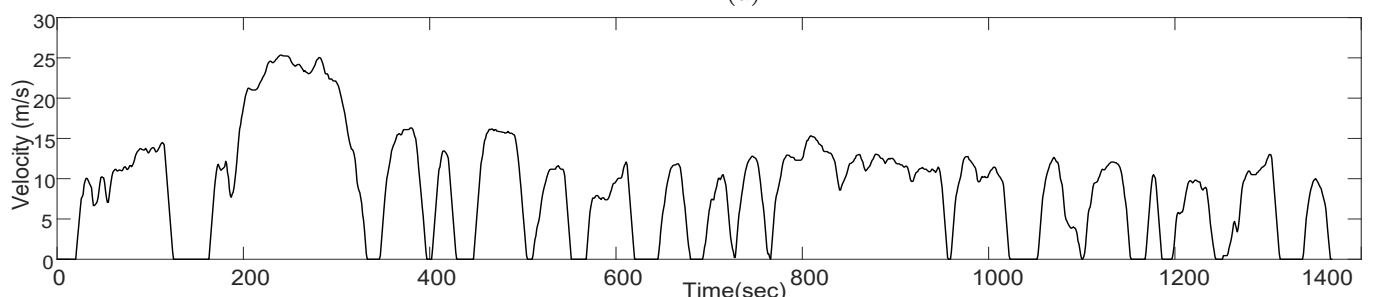

(b)

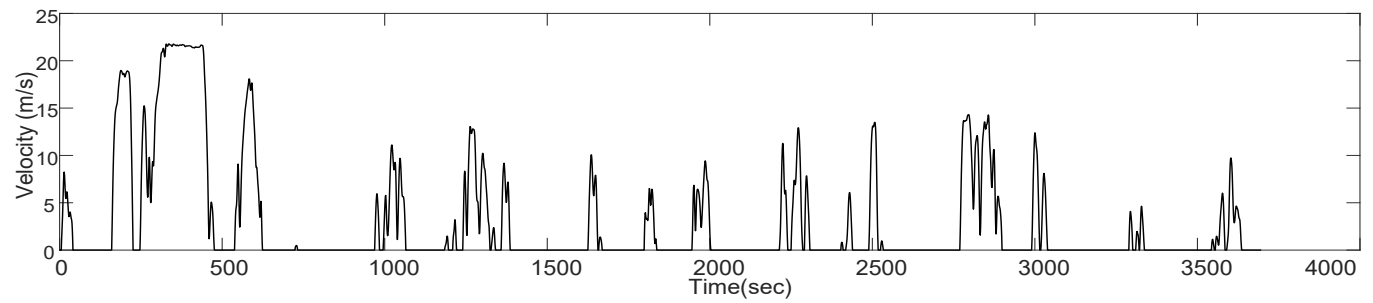

(c)

Figure 5. Drive cycles: (a) NEDC, (b) UDDS, (c) NREL

Simulations are carried out in Matlab/Simulink environment and EDV is assumed to be driven on a flat road and slope angle is taken zero. Results are analyzed in terms of SOC values and battery currents.

\subsection{SOC Values}

For each strategy, battery and supercapacitors are assumed to be fully charged at the beginning and initial SOC values are taken as 100 percent. Battery SOC vales obtained at the end of each drive cycle are given in Table 8. Beside the SOC levels for UDDS drive cycle obtained from all three strategies are given in Figure 6 .

Initial SOC and cycle-end SOC values of batteries for different strategies and for different drive cycles are given in Table 8. Initial SOC is state of the charge of battery at the beginning of drive cycle and cycle-end SOC is state of the charge of battery when the EDV arrive to the end of drive cycle. Initial SOC values are taken $\% 100$ for all conditions as mentioned before. As it is seen from Table 8, cycle-end SOC values take higher values when proposed fuzzy control method is applied for all drive cycles compared to the other strategies. In table 9, initial SOC, minimum SOC, and cycle-end SOC values of supercapacitors for different strategies and for different drive cycles are given.

As one can see from Table 9 fuzzy logic controller method have the lowest cycle-end supercapacitor

Table 8. Initial and cycle-end battery SOC values.

\begin{tabular}{|l|ccc|ccc|ccc|}
\cline { 2 - 10 } \multicolumn{1}{c|}{} & \multicolumn{4}{c|}{ Only Battery System } & \multicolumn{3}{c|}{ Logic Threshold Method } & \multicolumn{3}{c|}{ Fuzzy Control Method } \\
\cline { 2 - 10 } \multicolumn{1}{c|}{} & NEDC & UDDS & NREL & NEDC & UDDS & NREL & NEDC & UDDS & NREL \\
\hline Initial SOC (\%) & 100 & 100 & 100 & 100 & 100 & 100 & 100 & 100 & 100 \\
Cycle-end SOC (\%) & 92.90 & 92.50 & 91.30 & 94.00 & 93.00 & 91.90 & 94.29 & 94.00 & 93.00 \\
\hline
\end{tabular}

Table 9. Initial, minimum and cycle-end supercapacitor SOC values

\begin{tabular}{|l|ccc|ccc|}
\cline { 2 - 7 } \multicolumn{1}{c|}{} & \multicolumn{3}{c|}{ Logic Threshold Method } & \multicolumn{3}{c|}{ Fuzzy Control Method } \\
\cline { 2 - 7 } \multicolumn{1}{c|}{} & NEDC & UDDS & NREL & NEDC & UDDS & NREL \\
\hline Initial SOC (\%) & 100 & 100 & 100 & 100 & 100 & 100 \\
Minimum SOC (\%) & 8 & 55 & 71 & 8 & 21 & 13 \\
Cycle-end SOC (\%) & 22 & 73 & 51 & 25 & 23 & 16 \\
\hline
\end{tabular}




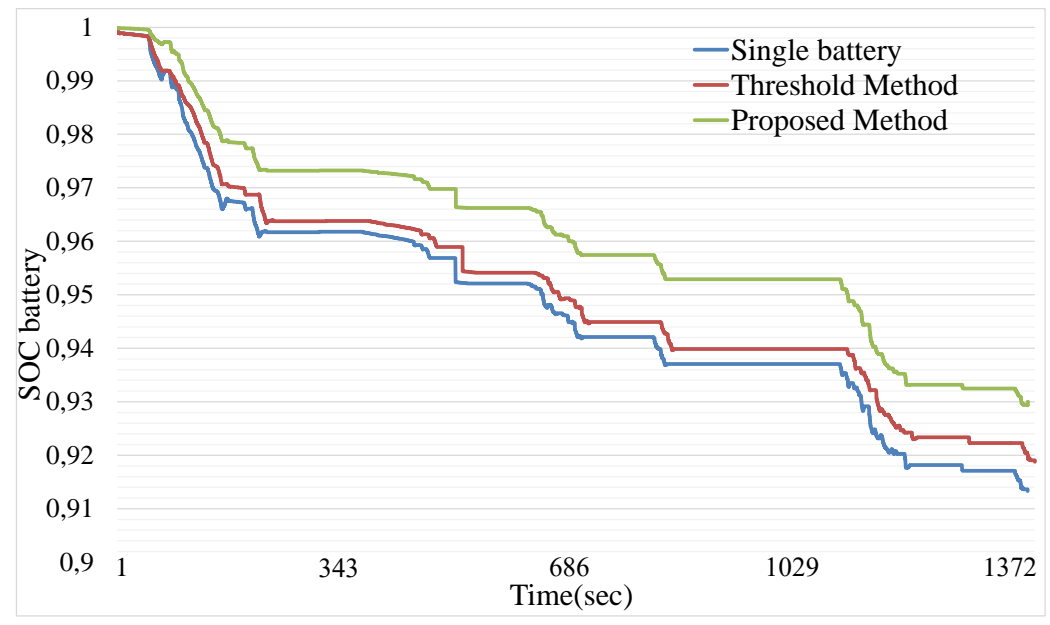

Figure 6. SOC values for three different strategies

SOC values which also means that supercapacitor power consumption is increased. This is quite reasonable because proposed method reduces the battery power consumption while EDV's total energy requirement is constant depending on the considered drive cycle. Also note that supercapacitor SOC values never drop to below $\% 5$ which is predefined as the lower limit value.

\subsection{Battery Currents}

For each strategy, battery charge and discharge currents obtained throughout simulations are given in Figure 7 and Table 10 .

As it is seen from Table 10 , in the case either logic treshold control or fuzzy logic control method is applied to manage dual storage system, both peak battery discharge and peak battery charge current values are considerably reduced for all drive cycles since supercapacitors support battery in both motoring and regenerating modes. Although logic threshold method gives the lowest battery peak discharge current values, proposed fuzzy control method improves the results in terms of avarage battery charge current values as seen in Figure 7. Also as seen from Figure 8 and Figure 7 not only the magnitude of battery charge currents but also the charging frequency of the battery are considerably decreased when the proposed fuzzy control method is applied. Battery power values for each strategy for UDDS drive cycle are given in Figure 8, As seen from Figure 8, batteries are consumed mainly in motoring mode and rarely charged. Therefore it can be concluded that battery lifespan is prolonged since the frequent charge and discharge of battery and high battery current values are avoided.

Furthermore peak charge and discharge currents of supercapacitor are given in Table 11. Note that charging / discharging currents of both supercapacitor and battery are under their predefined maximum limits.

\section{Conclusion}

In this manuscript, a fuzzy based energy management controller has been developed to allocate the instantaneous power between the battery and supercapacitor considering to prolong battery lifespan and the range of EDV. First, the model of EDV and dual storage system is studied, then fuzzy based energy management controller is designed, finally a simulations are carried

Table 10. Peak charge and discharge current values of battery for three different drive cycles.

\begin{tabular}{|l|ccc|ccc|ccc|}
\cline { 2 - 10 } \multicolumn{1}{c|}{} & \multicolumn{4}{c|}{ Only Battery System } & \multicolumn{3}{c|}{ Logic Threshold Method } & \multicolumn{3}{c|}{ Fuzzy Control Method } \\
& NEDC & UDDS & NREL & NEDC & UDDS & NREL & NEDC & UDDS & NREL \\
\hline Peak Discharge Current (A) & 111 & 117 & 108 & 110 & 60 & 60 & 102 & 97 & 97 \\
Peak Charge Current (A) & 50 & 50 & 66 & 20 & 20 & 20 & 5 & 15 & 20 \\
\hline
\end{tabular}

Table 11. Peak charge and discharge current values of supercapacitor for three different drive cycles.

\begin{tabular}{|l|ccc|ccc|}
\cline { 2 - 6 } \multicolumn{1}{c|}{} & \multicolumn{3}{c|}{ Logic Threshold Method } & \multicolumn{3}{c|}{ Fuzzy Control Method } \\
\cline { 2 - 6 } \multicolumn{1}{c|}{} & NEDC & UDDS & NREL & NEDC & UDDS & NREL \\
\hline Peak Discharge Current (A) & 650 & 650 & 640 & 195 & 257 & 331 \\
Peak Charge Current (A) & 290 & 305 & 400 & 263 & 263 & 282 \\
\hline
\end{tabular}




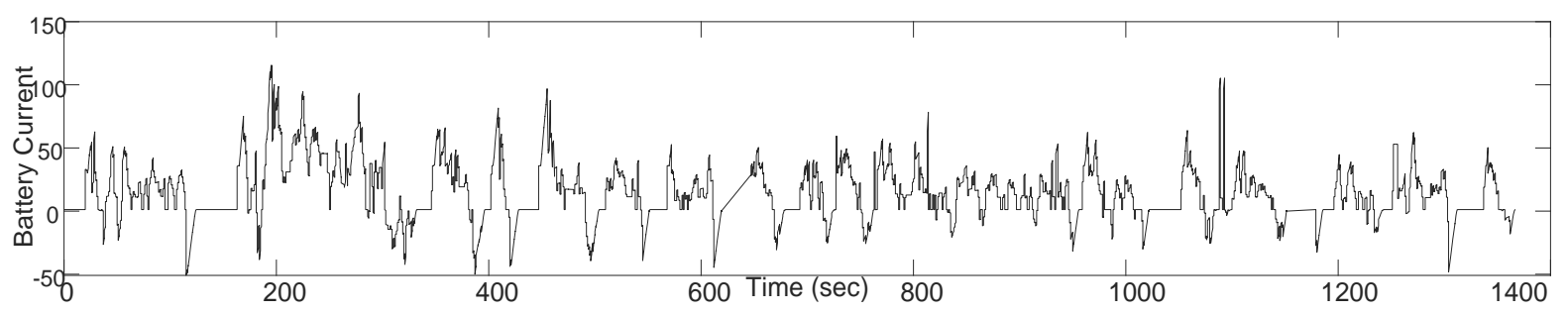

(a)

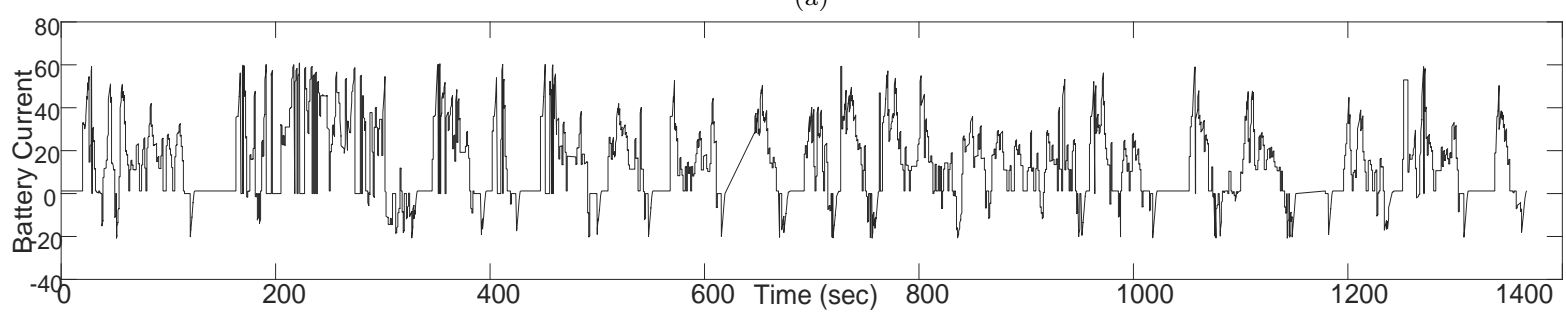

(b)

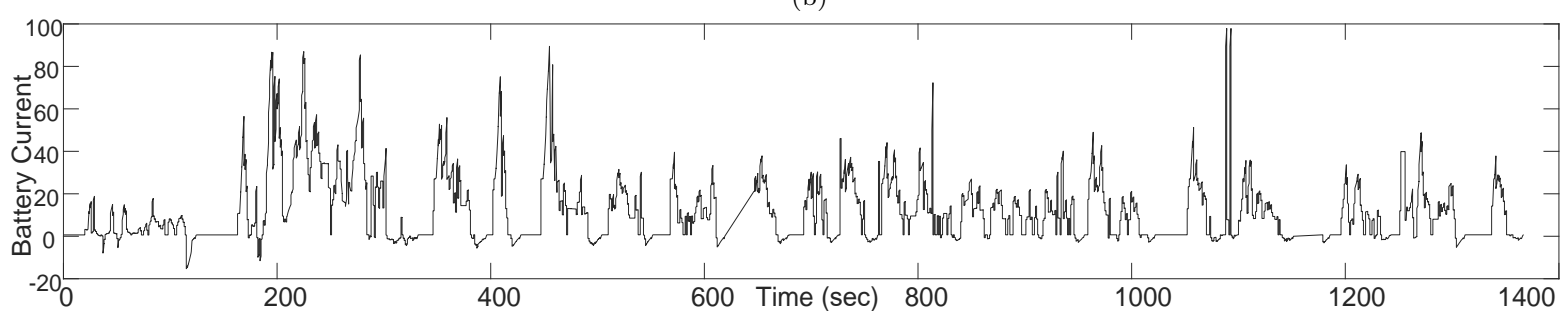

(c)

Figure 7. Battery currents of each strategy for UDDS drive cycle (a) Only battery system (b) Logic threshold (c) Fuzzy control

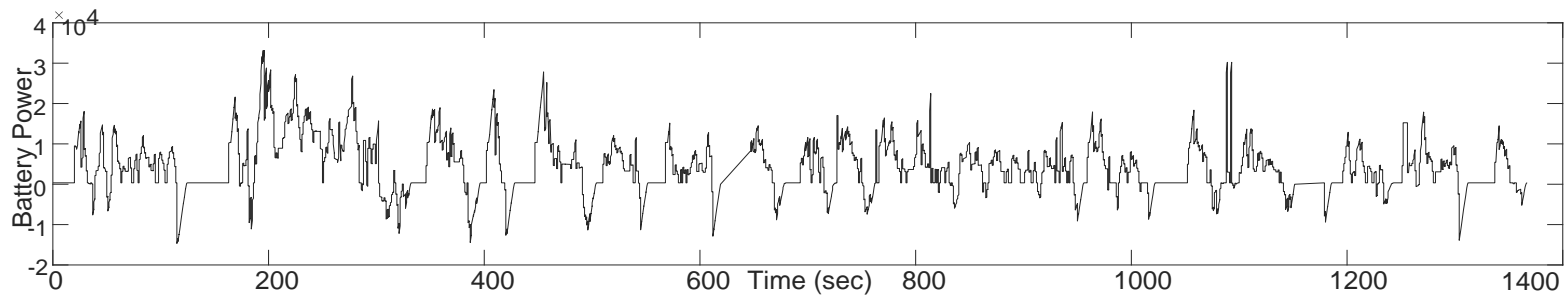

(a)

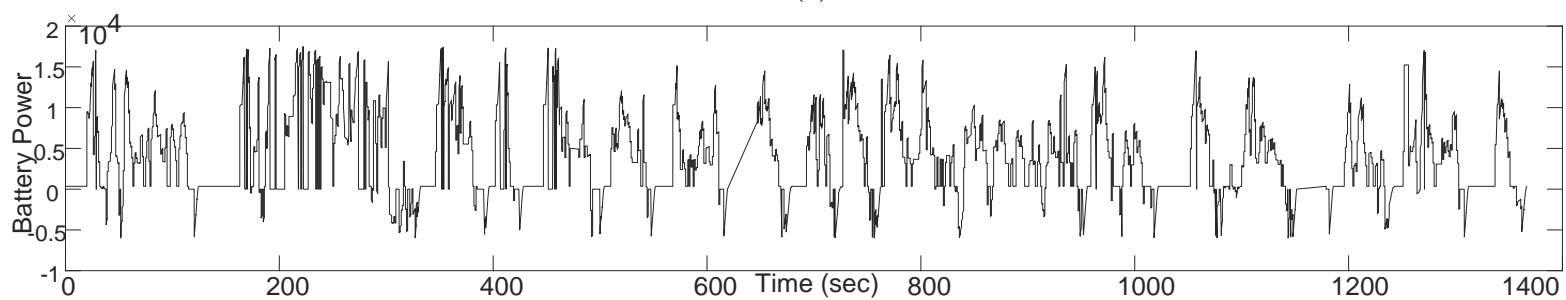

(b)

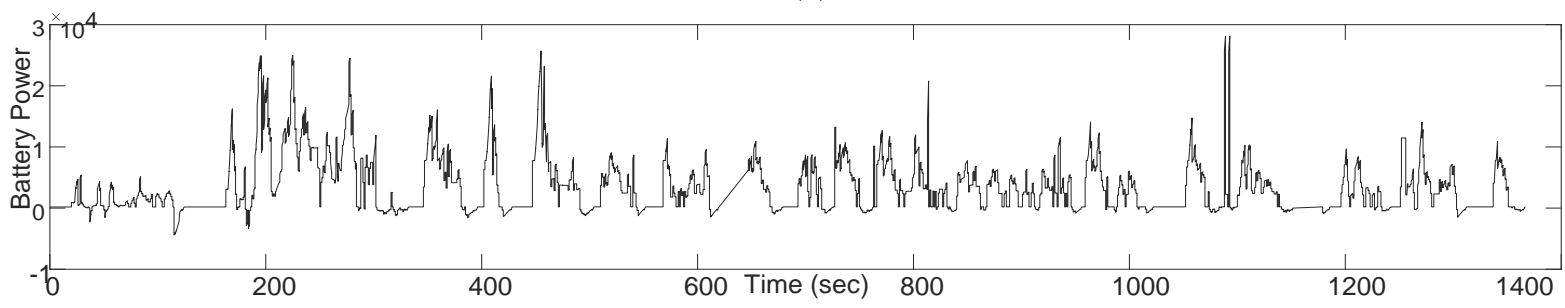

(c)

Figure 8. Battery powers of each strategy for UDDS drive cycle (a) Only battery system (b) Logic threshold (c) Fuzzy control

out in different drive cycles in Matlab/Simulink environment. The performance of the proposed method has been compared with two strategies: the battery only system and dual storage system managed with logic threshold method. The results show that, with the proposed method, the amount of power supplied by the battery is reduced by adding supercapacitors to the system. Besides both peak battery discharge and charge 
currents has been reduced for all drive cycles and the battery is much less exposed to high currents. Furthermore not only the magnitude of battery charge currents but also the charge frequency of the battery are considerably decreased. In consideration of these results, proposed method provides more effective battery energy usage and is helpful to prolong battery lifespan.

\section{References}

[1] Environmental Protection Agency(EPA) (2019). Invertory of U.S. Greenhouse Gas Emissions and Sinks, EPA 430-R-19-001.

[2] Chan, C. (2002). The state of the art of electric and hybrid vehicles. Proceedings of the IEEE, 90(2), 247-275.

[3] Burke, A. (2007). Batteries and Ultracapacitors for Electric, Hybrid, and Fuel Cell Vehicles. Proceedings of the IEEE, 95(4), 806-820.

[4] Landi, M. \& Gross, G. (2014). Measurement Techniques for Online Battery State of Health Estimation in Vehicle-to-Grid Applications. IEEE Transactions on Instrumentation and Measurement, 63(5), 1224-1234.

[5] Choi, M., Lee, J., \& Seo, S. (2014). RealTime Optimization for Power Management Systems of a Battery/Supercapacitor Hybrid Energy Storage System in Electric Vehicles. IEEE Transactions on Vehicular Technology, 63(8), 3600-3611.

[6] Auer, J., Sartorelli, G., \& Miller, J. (2006). A Gatekeeper energy management strategy for ECVT hybrid vehicle propulsion utilising ultracapacitors. IET - Hybrid Vehicle Conference. 79-90.

[7] Kouchachvili, L., Yaici W., \& Entchev, E. (2018). Hybrid battery/supercapacitor energy storage system for the electric vehicles. Journal of Power Sources. 374, 237-248.

[8] Khaligh A., \& Li, Z. (2010). Battery, Ultracapacitor, Fuel Cell, and Hybrid Energy Storage Systems for Electric, Hybrid Electric Fuel Cell, and Plug-In Hybrid Electric Vehicles: State of the Art. IEEE Transactions on Vehicular Technology. 59(6), 2806-2814.

[9] Zhang, S., Xiong, R. \& Cao, J. (2016). Battery durability and longevity based power management for plug-in hybrid electric vehicle with hybrid energy storage system. Applied Energy. 179, 316-328.

[10] Fadil, H., Giri, F., Guerrero, J., \& Tahri, A. (2014). Modeling and Nonlinear Control of a Fuel Cell/Supercapacitor Hybrid Energy Storage System for Electric Vehicles. IEEE Transactions on Vehicular Technology. 63(7), 3011-3018.
[11] Song, Z., Hou, J., Hofmann, H., Li, J., \& Ouyang, M. (2017). Sliding-mode and Lyapunov function-based control for battery/supercapacitor hybrid energy storage system used in electric vehicles. Energy. 122, 601-612.

[12] Salazar M., Balerna, C., Elbert, P., Grando, F., \& Onder, C. (2017). Real-Time Control Algorithms for a Hybrid Electric Race Car Using a Two-Level Model Predictive Control Scheme. IEEE Transactions on Vehicular Technology. 66(12), 10911-10922.

[13] Song, Z., Li, J., Hou, J., Hofmann, H., Ouyang, M., \& Du, J. (2018). The batterysupercapacitor hybrid energy storage system in electric vehicle applications: A case study. Energy. 154, 433-441.

[14] Li, Q., Chen, W., Liu, Z., Li, M., \& Ma, L. (2015). Development of energy management system based on a power sharing strategy for a fuel cell-battery-supercapacitor hybrid tramway. Journal of Power Sources. 279, 267-280.

[15] Xiong, R., Cao, J., \& Yu, Q. (2018). Reinforcement learning-based real-time power management for hybrid energy storage system in the plug-in hybrid electric vehicle. Applied Energy. 211, 538-548.

[16] Moreno, J., Ortuzar, M. E., \& Dixon, J. W. (2006). Energy-management system for a hybrid electric vehicle, using ultracapacitors and neural networks. IEEE Transactions on Industrial Electronics. 53(2), 614-623.

[17] Shen, J., \& Khaligh, A. (2015). A Supervisory Energy Management Control Strategy in a Battery/Ultracapacitor Hybrid Energy Storage System. IEEE Transactions on Transportation Electrification. 1(3), 223-231.

[18] Islam, M., Yang, F., Ekanayek, C., \& Amin, M. (2018). Grid power fluctuation reduction by fuzzy control based energy management system in residential microgrids. International Transactions on Electrical Energy Systems. 29(3), 2758.

[19] Arcos-Aviles, D., Pascual, J., Marroyo, L., Sanchis, P., \& Guinjoan, F. (2018). Fuzzy Logic-Based Energy Management System Design for Residential Grid-Connected Microgrids. IEEE Transactions on Smart Grid. 9(2), 530-543.

[20] Prathyush, M., \& Jasmin, E. A. (2018). Fuzzy Logic Based Energy Management System Design for AC Microgrid, in 2018 Second International Conference on Inventive Communication and Computational Technologies (ICICCT). 
[21] Xiong, W., Zhang, Y., \& Yin, C. (2009). Configuration design, energy management and experimental validation of a novel series-parallel hybrid electric transit bus. Journal of Zhejiang University-SCIENCE A. 10(9), 12691276.

[22] Madani, O., Bhattacharjee, A., \& Das, T. (2016). Decentralized Power Management in a Hybrid Fuel Cell Ultracapacitor System. IEEE Transactions on Control Systems Technology. 24(3), 765-778.

[23] Mitschke, M., Dynamik der Kraftzeuge (1995). Band A- Antrieb und Bremsung. 3rd ed. Springer Publication.

[24] Bhatt, A. (2016). Planning and application of Electric Vehicle with MATLAB@/Simulink®. In 2016 IEEE International Conference on Power Electronics, Drives and Energy Systems (PEDES).

[25] Jun, R., Kai, W., \& Liwei, L. (2017). Characteristics analysis of ultracapacitor-battery hybrid energy storage system, in 2017 Chinese Automation Congress (CAC).

[26] Zadeh, L. (1988). Fuzzy logic. Computer. 21(4), 83-93.

[27] Yang, G., Li, J., Fu, Z., \& Fang, L., (2018). Optimization of logic threshold control strategy for electric vehicles with hybrid energy storage system by pseudo-spectral method. Energy Procedia. 152, 508-513.

[28] Yuan, Y., Zhang, J., Li, Y. \& Li, C. (2018). A Novel Regenerative Electrohydraulic Brake System: Development and Hardware-in-Loop Tests. IEEE Transactions on Vehicular Technology. 67(12), 11440-11452.

Kemal Keskin received his B.Sc. degree from Dumlupinar University, Kutahya, Turkey, in 2006. He received his M.Sc degree from Northeastern University, Boston, USA, in 2009 and he received Ph.D. degree from Eskisehir Osmangazi University, Eskisehir, Turkey, in 2016. He is currently working as assistant professor at Electrical and Electronics Engineering Department of Eskişehir Osmangazi University, Eskisehir, Turkey. His research interests include optimization, control systems and artificial intelligence.

(D) https://orcid.org/0000-0002-3969-2396

Burak Urazel received his B.Sc. degree from Anadolu University, Eskişehir, Turkey, in 2008, his M.Sc and Ph.D. degrees from Eskişehir Osmangazi University, Eskisehir, Turkey, in 2011 and in 2017. He is currently working as an assistant professor at the Electrical and Electronics Engineering Department of Eskişehir Osmangazi University, Eskisehir, Turkey. His research interests include optimization methods and their application in power systems.

(D) https://orcid.org/0000-0002-3221-9854

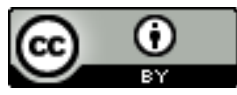

This work is licensed under a Creative Commons Attribution 4.0 International License. The authors retain ownership of the copyright for their article, but they allow anyone to download, reuse, reprint, modify, distribute, and/or copy articles in IJOCTA, so long as the original authors and source are credited. To see the complete license contents, please visit http://creativecommons.org/licenses/by/4.0/. 